\title{
New Advances in the Understanding of the In-Source Decay Fragmentation of Peptides in MALDI-TOF-MS
}

\author{
Kevin Demeure, Valérie Gabelica, and Edwin Andre De Pauw \\ General and Physical Chemistry Department, Mass Spectrometry Laboratory, Liege University, Liege, \\ Belgium
}

\begin{abstract}
In-source decay (ISD) is a rapid fragmentation occurring in the matrix-assisted laser desorption/ionization (MALDI) source before the ion extraction. Despite the increasing interest for peptides de novo sequencing by ISD, the influence of the matrix and of the peptide itself is not yet fully understood. Here we compare matrices with high ISD efficiencies to gain deeper insight in the ISD fragmentation process(es). The major ISD fragments are the $c$ - and $z$-ions, but other types of fragments are also observed, and their origin is studied here. Two main pathways lead to fragmentation in the source: a radical-induced pathway that leads to $c_{--}, z_{-}, w_{-}$, and $d$-ions, and a thermally activated pathway that leads to $y-, b$-, and $a$-ions. A detailed analysis of the ISD spectra of selected peptides revealed that (1) the extents of the two in-source pathways are differently favored depending on the matrix used, that (2) the presence of a positive/negative charge on the radical-induced fragments is necessary for their observation in positive/negative mode, respectively, and that (3), for a same peptide, the patterns of the different types of fragments differ according to the matrix used. (J Am Soc Mass Spectrom 2010, 21, 1906-1917) (c) 2010 American Society for Mass Spectrometry
\end{abstract}

$\mathrm{M}$ atrix-assisted laser desorption/ionization (MALDI) [1-3] is a widely used technique for the analysis of biopolymers [4-9], especially peptides and proteins. In-source decay (ISD) $[10,11]$ is a fragmentation occurring in the MALDI source, rapidly after the laser shot and before the ion extraction. ISD fragments are therefore detected at the correct $\mathrm{m} / \mathrm{z}$ ratios in MS mode. On the contrary, fragments formed after the ion extraction are not resolved in MS mode, and can only be revealed by MS/MS in dual stage time-of-flight instruments [12], or by a stepwise lowering of the reflectron voltage in the so-called PSD (post source decay) mode [13, 14]. ISD of peptides and proteins mainly leads to $c$ - and $z$-ions $[15,16]$, and the consensus explanation is that those fragments come from a reduction of the parent ion by hydrogen radicals coming from the matrix [17, 18]. Nevertheless, other fragments such as $a-, b-$, and $y$-ions have also been reported to form in the MALDI source [4, 7-9, 19, 20]. PSD leads mainly to similar fragments as those formed by low-energy collision-induced dissociation $(a-, b-$, and $y$-ions) [21, 22].

Contrary to CID-like fragments, the radical-induced ISD fragments ( $c$ - and $z$-ions) have the advantage of being theoretically not limited in mass. Indeed, in CID

Address reprint requests to Professor E. A. De Pauw, General and Physical Chemistry Department, Mass Spectrometry Laboratory, Liege University, Allée de la Chimie 3, B-4000 Liege, Belgium. E-mail: e.depauw@ulg.ac.be experiments, the internal energy received by the peptide is distributed amongst all its degrees of freedom, i.e., they undergo intramolecular vibrational-energy redistribution (IVR). Therefore, the larger the peptide, the less the energy received per degree of freedom, decreasing the fragmentation efficiency. Like in electron capture dissociation (ECD) $[23,24]$, because the production of $c$ - and $z$-ions results from a radical-driven process that takes place before the completion of the IVR (non-ergodic process), ISD fragmentation efficiency does not depend on the mass of the peptide and allows to sequence larger peptides as well as intact proteins $[5,10]$.

In the present work, we address the mechanisms of in-source formation of the different fragment types. The difficulty in addressing these mechanisms comes from the fact that the nature of the fragments depends both on the matrix and on the peptide sequence. The matrix influences the fragmentation pathways for different reasons $[25,26]$. (1) The extent of hydrogen radical production in the matrix plume influences the radicalinduced pathway. (2) The exothermicity of proton transfer from the matrix to the analyte influences the thermal pathway and also depends on the analyte. (3) The plume expansion dynamics, and hence the time evolution of the collision probabilities influence both pathways.

This paper mainly focuses on the determination of the influence of the matrix and of the peptide on the observation and on the extent of both pathways of frag- 
mentation. Our study includes the following matrices: the classic 2,5-DHB (2,5-dihydroxybenzoic acid) and CHCA ( $\alpha$-cyano-4-hydroxycinnamic acid) matrices, the highly ISD efficient 1,5-DAN (1,5-diaminonaphthalene) [27, 28], and the 5-aminosalicylic acid (5-ASA) matrix, recently used by Sakakura and Takayama [29].

The hydrogen donor abilities of different matrices were previously determined [27] with spirooxazines (hydrogen scavengers) [30,31], but this method suffers from some limitations. The high radical-induced ISD efficiency of the 1,5-DAN matrix was revealed by its high capacity to reduce intra- and intermolecular disulfide bonds of bovine insulin [27, 32]. Here we used a small peptide (3-4 $\mathrm{kDa}$ ) with one intramolecular disulfide bond to classify the matrices according to their yield of hydrogen radical transfer to the analyte (i.e., their radical-induced ISD efficiency).

Concerning the thermal pathway, it has been suggested that the internal energy of the analyte is correlated with the exothermicity of the proton exchange from the matrix to the peptide evaluated with their respective gas-phase proton affinities (PAs) [26, 33, 34]. We therefore also calculated the proton affinities of 1,5-DAN and 5-ASA, which were not reported before.

The radical-induced ISD fragmentation is independent of the ionization process [11, 19] and can be considered as a charge-remote fragmentation [35]. The influence of the peptide sequence of the peptide sequence was studied because, as they are mainly observed as singly charged ions in MALDI, the location of the charge can influence whether $\mathrm{N}$-terminal or Cterminal fragments can be observed [8, 19].

\section{Experimental}

\section{Materials}

$\alpha$-Cyano-4-hydroxycinnamic acid (CHCA), 2,5dihydroxybenzoic acid (2,5-DHB), 5-aminosalicylic acid (5-ASA), picolinic acid (PA), formic acid (FA), oxidized insulin $\beta$-chain (3493.6 Da) were purchased from SigmaAldrich (Steinheim, Germany). 1,5-Diaminonaphthalene (1,5-DAN) was purchased from Acros (Geel, Belgium). The peptides calcitonin (salmon I) (3431.9 Da), (Tyr $\left.{ }^{0}\right)-\mathrm{C}-$ Peptide (dog) (3337.7 Da), (Glu $\left.{ }^{1}\right)$-fibrinopeptide B (1570.6 $\mathrm{Da}), \beta$-endorphin (rat) (3466.1 Da), acetyl-calpastatin (184210) (human) (3177.7 Da), ACTH (7-38) (human) (3659.2 $\mathrm{Da})$, acetyl-Amylin (human) (8-37) (3225.5 Da), neuropeptide W30 (rat) (3559.2 Da), GLP-2 (rat) (3796.2 Da), amyloid $\beta$-protein (1-28) (3262.5 Da) were purchased from Bachem (Weil am Rhein, Germany). All the solvents used were HPLC grade quality (purity $>99.9 \%$ ).

\section{Sample Preparation}

2,5-DHB and picolinic acid (PA) solutions were prepared in $\mathrm{H}_{2} \mathrm{O}(0.1 \% \mathrm{FA}) / \mathrm{ACN}(1 / 1)$ at $20 \mathrm{mg} / \mathrm{mL}$. CHCA solutions were prepared at $40 \mathrm{mg} / \mathrm{mL}$ in $\mathrm{H}_{2} \mathrm{O}$ $(0.1 \% \mathrm{FA}) /$ acetone in a $3 / 97$ ratio (vol:vol). 1,5-DAN solutions were prepared in $\mathrm{H}_{2} \mathrm{O}(0.1 \% \mathrm{FA}) / \mathrm{ACN}(1 / 1)$ at saturation $<20 \mathrm{mg} / \mathrm{mL})$. The $1,5-\mathrm{DAN}$ solutions were prepared shortly before the MS experiments because of the instability of 1,5-DAN in acetonitrile [36]. The 1,5-DAN/PA mixture was prepared by mixing the 1,5 -DAN solution and the PA solution in a $75 / 25$ ratio (vol:vol). Peptides were prepared in bi-distilled water at concentrations of $2 \times 10^{-5} \mathrm{M}$. The exact same sample preparation was used for positive and negative ion mode experiments.

PA is not an ISD active reagent; it makes the matrix crystals more resistant to the laser irradiation (no crystal movement or ejection) and enhances the ion signals in both ion modes while preserving the radical-induced ISD efficiency of 1,5 -DAN. $1,5-\mathrm{DAN}$ is a toxic chemical [37] to use with caution. 5-ASA is non-toxic.

\section{Mass Spectrometry}

All MALDI mass spectrometry experiments were carried out in the reflectron mode on an Ultraflex II TOF/TOF mass spectrometer (Bruker Daltonics, Bremen, Germany) equipped with a frequency tripled Nd:YAG laser (Smartbeam technology) with a laser wavelength of $355 \mathrm{~nm}, 6 \mathrm{~ns}$ pulse width, and a focal spot size between 60 and $70 \mu \mathrm{m}$ (Bruker Daltonics). The instrument is operated using Flexcontrol 3.0 (Bruker Daltonics). The instrument was used in reflectron mode. The ion accelerating voltage was $25 \mathrm{kV}$ with the voltages of the electrodes 1 and 2 set at $86.8 \%(21.7 \mathrm{kV})$ and $38 \%$, respectively, to carry out the pulsed ion extraction (PIE). The time delay before the ion extraction was set at 190 ns. Experiments with various time delays (60 to $650 \mathrm{~ns}$ ) before ion extraction were also performed but no clear differences of relative fragments intensities could be observed. The dried droplet method was used for all spot preparations (except for CHCA): $0.5 \mu \mathrm{L}$ of matrix solution and $0.5 \mu \mathrm{L}$ of analyte were deposited on the MALDI plate and allowed to dry at ambient temperature or by heating with a blow-dryer (for 2,5-DHB), leading to the crystallization of the sample. For CHCA, each spot was prepared using the thin-layer method: a Gilson's Microman (The Hague, The Netherlands) pipette was used to deposit on the Anchorchip MALDI plate (Bruker, Bremen, Germany) a small quantity $(\approx 0.2 \mu \mathrm{L})$ of matrix solution that immediately crystallizes in a thin-layer of small and homogeneous matrix crystals. $0.5 \mu \mathrm{L}$ of analyte solution was then deposited on the thin-layer of matrix and allowed to dry at ambient temperature. After solvent evaporation, the sample was washed with a solution of ammonium phosphate at $10 \mathrm{mM}$ in $\mathrm{H}_{2} \mathrm{O}$ (TFA $0.1 \%$ ). One droplet of this wash solution was deposited on the freshly prepared spot and immediately removed. The sample was again allowed to dry at ambient temperature before the MS experiments.

Calibrations were made with each matrix using the intense $c$-ions observed in the ISD spectra of the acetylAmylin (human) peptide. The mass error for the cali- 
bration curve is up to $20 \mathrm{ppm}$. Mass accuracies between 100 and 150 ppm for all the assigned fragments were obtained with external calibration, ensuring their correct identification. Two thousand five hundred laser shots (by series of 100 laser shots) were acquired for each spectrum, at different places on the MALDI spot. The laser attenuator and the laser offset were $64 \%$ and $15 \%$, respectively. The laser intensities at the peptide ionization threshold (laser intensity at which the S/N of the peptide molecular ion becomes $\geq 3$ ) determined for 2,5-DHB, 1,5-DAN, 1,5-DAN/PA, and 5-ASA are 30\%, $35 \%, 33 \%$, and $75 \%$, respectively. For each matrix or matrix mixture used, the laser fluence used was $10 \%$ above the peptide ionization threshold for the acquisition of ISD spectra. The same or slightly higher (15\% above the peptide ionization threshold) laser fluence was used in the negative ion mode. For the analysis of the molecular ion of calcitonin (salmon I) and the measurement of the radical-induced ISD percentages, the laser fluence used was 5\% above the peptide ionization threshold. Experiments were repeated at least 15 times, five times on three different fresh MALDI spots of the same preparation. For 1,5-DAN matrix-based preparations, only the needle-shaped crystals were used for the mass spectral acquisition because those that do not crystallized properly do not produce intense signals. Supplementary material Figure S-1, which can be found in the electronic version of this article, shows a photograph of the 1,5-DAN crystallization with both types of crystals. For the determinations of the percentages of ISD fragmentation, only the $c$ - and $z$-ions above $1000 \mathrm{Da}$ (not disturbed by the matrix cluster area) were taken into account.

\section{Data Analysis Software}

Biotools 3.0 and DataAnalysis 3.4 (Bruker Daltonics) were used for fragment assignment and analysis.

\section{Ab Initio Calculations}

All calculations were carried out using the Gaussian 03 package (rev. D.02) [38]. Geometry optimizations and the vibrational frequency calculations were carried out at the B3LYP/6-31+G(d,p) level. The final energy calculations of the most stable geometries were carried out at the B3LYP $/ 6311+\mathrm{G}(2 \mathrm{~d}, 2 \mathrm{p})$ level. The proton affinity of a matrix $\mathrm{M}$ was calculated as the enthalpy change, by the eq 2, at $298 \mathrm{~K}$ in reaction 1 [39]:

$$
\begin{aligned}
{[\mathrm{M}+\mathrm{H}]^{+} } & \rightarrow \mathrm{M}+\mathrm{H}^{+} \\
\mathrm{PA}_{(298 \mathrm{~K})}= & \Delta \mathrm{E}_{\text {elec }}+298 \mathrm{R}+\Delta \mathrm{E}_{\text {therm }}+\Delta \mathrm{E}_{\text {rot(298 K })} \\
& +\Delta \mathrm{E}_{\text {trans }(298 \mathrm{~K})}
\end{aligned}
$$

where $\Delta \mathrm{E}_{\text {elec }}$ is the variation in electronic internal energy calculated at the B3LYP/6-311+G(2d,2p) level; $298 \mathrm{R}=2.5 \mathrm{~kJ} / \mathrm{mol}$ (conversion of the internal energy in enthalpy in the ideal gases approximation); $\Delta \mathrm{E}_{\text {therm }}$ (variation in thermal energy at $298 \mathrm{~K}$ ) is derived by computed harmonic frequencies at the B3LYP/6$31+\mathrm{G}(\mathrm{d}, \mathrm{p})$ level. $\Delta \mathrm{E}_{\text {rot(298 K) }}+\Delta \mathrm{E}_{\text {trans(298 K) }}$ represents the corrections due to translation and rotation and can be estimated to [39]: $\Delta \mathrm{E}_{\operatorname{rot}(298 \mathrm{~K})}=0$ and $\Delta \mathrm{E}_{\operatorname{trans}(298 \mathrm{~K})}=$ $3 / 2 \mathrm{RT}=3.7 \mathrm{~kJ} / \mathrm{mol}$.

\section{Results and Discussion}

Influence of the Matrix on the Yield of Hydrogen Radical Production and Correlation with the Yield of $c$ - and $z$-Ions

The estimation of the radical-induced ISD efficiency using a disulfide-bridged peptide has several advantages and is a good alternative to spirooxazines method [27]. Indeed, spirooxazines are low molecular weight molecules which signal falls in the $m / z$ where the matrix clusters can prevent their correct observation. Moreover, the ionization of spirooxazines in a matrix does not necessary imply that peptides or proteins will be correctly ionized by this matrix. For the use of a disulfide-bridged peptide, it is trivial to find a peptide including one disulfide bond and which molecular mass is outside matrix cluster area $(m / z=100-1000)$. In addition, the ability of a matrix to ionize peptides is verified in the same experiment. Here we used calcitonin (salmon I), which contains one intramolecular disulfide bridge. The spectra were acquired in the different matrices, and the isotopic distributions were deconvoluted to assess the degree of reduction. Supplementary Figure S-2 shows the deconvolutions of the experimental isotopic distributions of the calcitonin molecular ion observed in 2,5-DHB and 1,5-DAN/PA in the contributions of the reduced and non-reduced forms.

Figure 1 shows the isotopic distributions of the molecular ion of Calcitonin (salmon I), not reduced in solution, obtained in 2,5-DHB (Figure 1a) and in 1,5DAN (Figure 1b). The MALDI process in 2,5-DHB reduces the disulfide bond, but to a much lower extent than in 1,5-DAN, which higher reductive ability has already been demonstrated [32]. Quantitatively, CHCA gives $2.2 \% \pm 1.5 \%$ of reduced form, 2,5-DHB gives $21 \% \pm 5 \%, 5$-ASA gives $40 \% \pm 5 \%$, and 1,5 -DAN gives $84 \% \pm 1 \%$. For comparison, the percentages of in-source formation of $c$ - and $z$-ions (the ratio between the total area of these fragments and the area of the molecular ion) were measured for these three matrices with the peptide acetyl-amylin (human). The increasing order of the measured matrix efficiencies to produce $c$ - and $z$-ions (i.e., their radical-induced ISD abilities) is the following: $2,5-\mathrm{DHB}$ gives $2.8 \% \pm 0.3 \%$ of radicalinduced ISD fragmentation, 5 -ASA gives $13.5 \% \pm 1.7 \%$, 


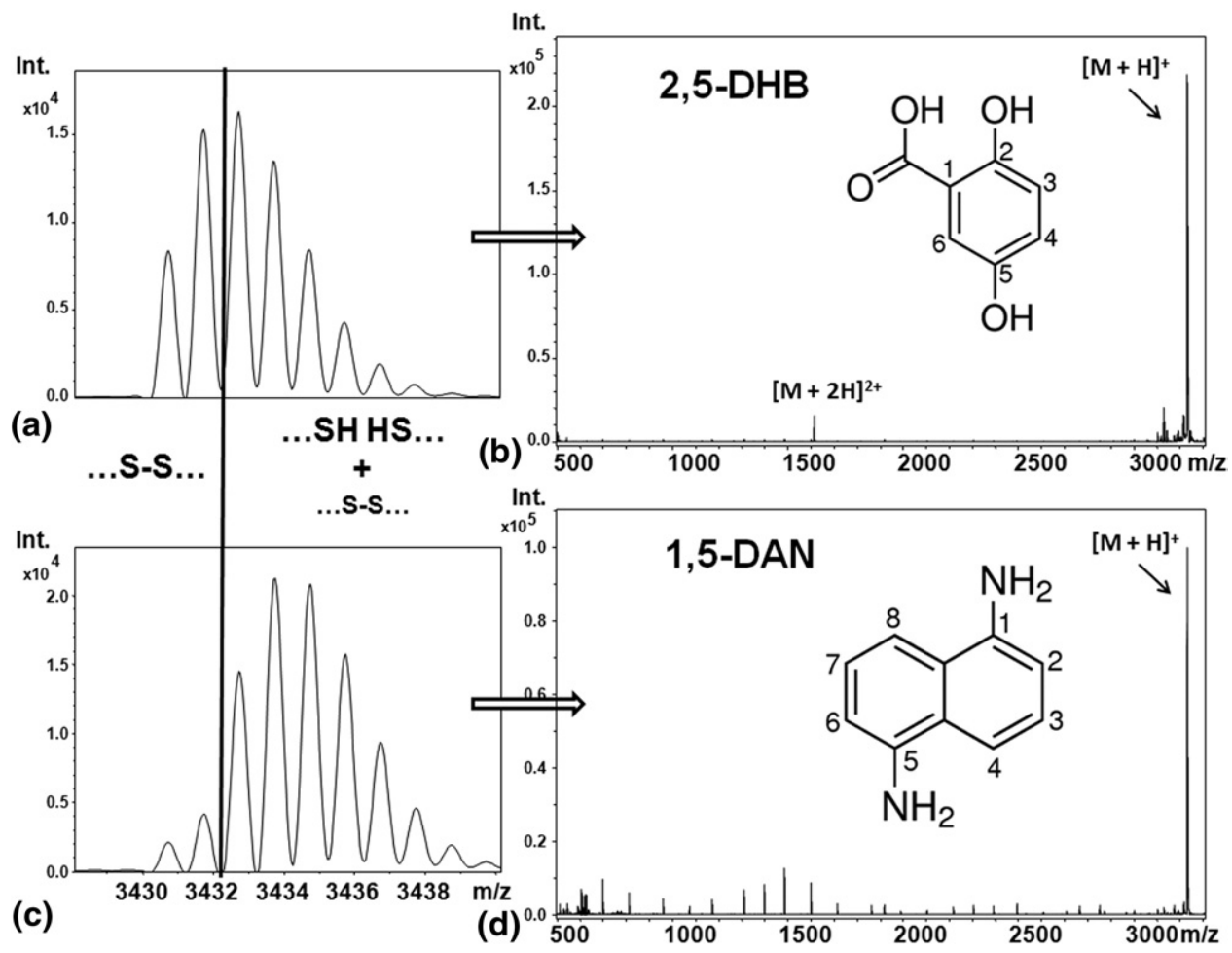

Figure 1. Experimental isotopic distributions of the molecular ion of the Calcitonin (salmon I) in 2,5-DHB (a) and in 1,5-DAN (b). The first two peaks correspond to the non-reduced form (...S-S . . .) and the other peaks to the reduced form (... SH HS ...) with the isotopic contribution of the non-reduced form. Their deconvolutions are represented in Figure S-1. On the right are represented the ISD spectra of the acetyl-Amylin (human) acquired in 2,5-DHB (c) and in 1,5-DAN (d) at higher laser intensity ( $5 \%$ higher) than for the analysis of the molecular ion of the calcitonin. The reduction of the disulfide bond (calcitonin) and the ISD spectra of the ac-amylin (human) observed in both matrices show that the matrix with the greatest reducing power favors the radical-induced pathway.

and 1,5-DAN gives $28 \% \pm 3 \%$. All errors are standard deviations from 15 measurements.

The increasing order of the reductive abilities of the matrices agrees with that of their radical-induced ISD efficiencies (1,5-DAN > 5-ASA > 2,5-DHB $\gg$ CHCA). These results confirm the correlation between the abilities of a matrix to reduce disulfide bonds and to promote radical-induced ISD (Figure 1 and S-2).

It is noteworthy that the reduction of the disulfide bond is favored over the radical-induced ISD fragmentation. In 2,5-DHB, the fragments between the two cysteines of the calcitonin (salmon I) are only observed when the disulfide bond is chemically reduced beforehand. In 1,5-DAN, these fragments are observed even when the disulfide bond is not reduced beforehand. However, they are produced to a higher extent when the disulfide bond is chemically reduced (data not shown).

\section{Proton Affinity of the Matrices and Correlation with the Yield of $a-, b$-, and $y$-Ions Via the Thermal Pathway}

For the different peptides, the various types of ISD fragments observed in the different matrices were stud- ied and compared for a same peptide to evaluate the extent of the thermal fragmentation pathway (the CIDlike $a-, b-$, and $y$-ions) according to the matrix used. The evaluation of the percentages of thermal fragments produced by the different matrices is difficult because the formation of CID-like fragments is more dependent on the laser fluence than the radical-induced ISD fragments. Moreover, 1,5-DAN only produces little amounts of thermal fragments. However, a qualitative ranking can be made, as the matrix is the most influent factor. The matrix ranking, from the least to the most efficient to produce thermal fragments, is as follows: 1,5 -DAN $<$ 5-ASA $\sim$ 2,5-DHB. As shown in Figures 2 and 3, 2,5-DHB and 5-ASA highly favor the CID-like $y-, a-$, and $b$-ions of the acetyl-calpastatin and of the acetyl-amylin (human), compared with 1,5-DAN. No further degradation of $y$-ions to $z$-ions (absence of $z^{\prime \prime}{ }_{18}$ and $z_{19}^{\prime \prime}$ in Figure 2) either of $c$-ions to $a$ - or $b$-ions is observed, confirming the independence of the two in-source fragmentation pathways. Roepstorff et al.'s [15] and Biemann's nomenclature [16] was used to denominate the different fragment types. To distinguish the negative and the positive fragment ions, double prime are added to the positive ions to highlight the difference of two daltons with the corresponding negative ions. The 


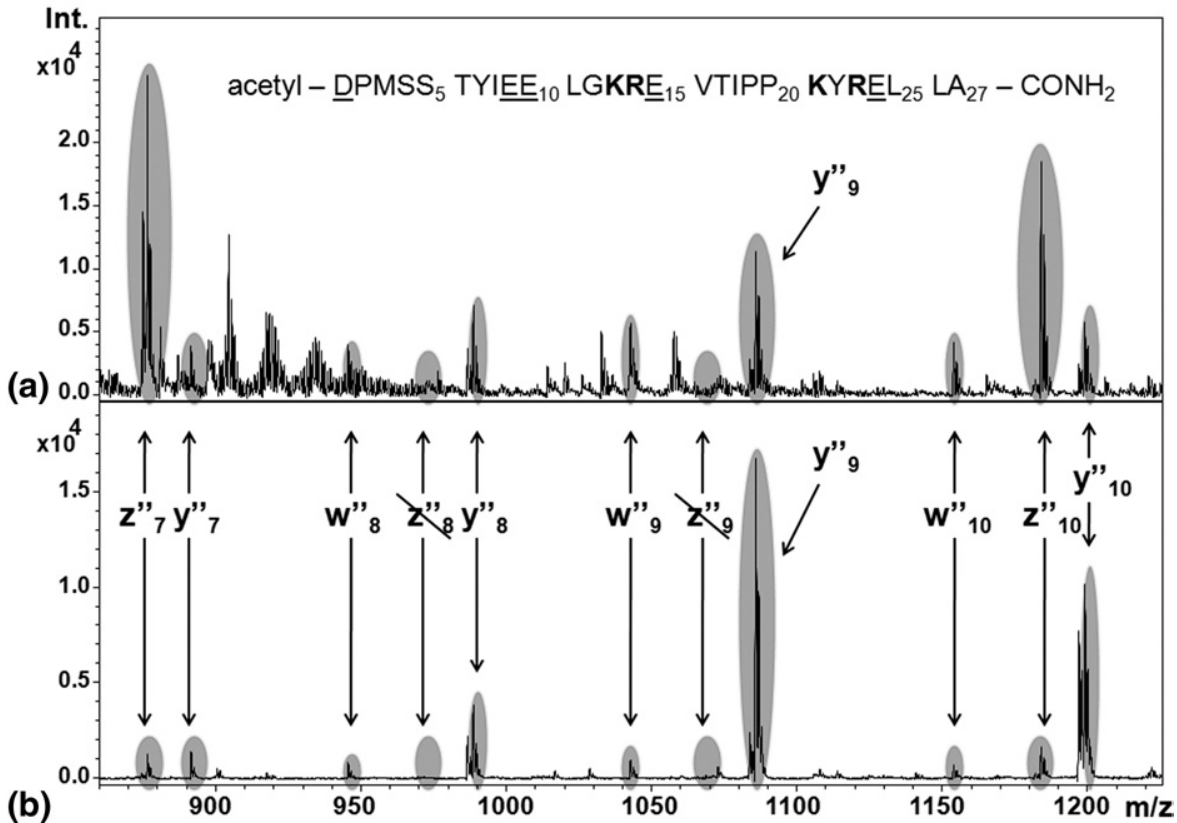

Figure 2. Zoom of the ISD spectra (in the positive ion mode) of the acetyl-calpastatin in the 850-1250 $\mathrm{m} / \mathrm{z}$ range in 1,5-DAN/PA (a) and in 2,5-DHB (b). The sequence of the peptide is indicated in the figure [basic amino acids arginine $(\mathrm{R})$, histidine $(\mathrm{H})$ and lysine $(\mathrm{K})$ ] are given in bold print. Acidic amino acids [aspartic acid (D) and glutamic acid (E) are underlined]. Shaded areas highlight the absence of the fragments $z^{\prime \prime}{ }_{8}$ and $z_{9}{ }_{9}$ and facilitate the comparison of the fragments of interest. The fragments $z_{8}{ }_{8}$ and $z_{9}^{\prime \prime}$ are not observed due to the presence of proline residues at positions 19 and 20. The corresponding $w$-ions are nevertheless formed by a rearrangement of the intermediate $z^{\bullet}$-ions (Scheme $\mathbf{1}$ ).

primes will be generally omitted except for denominating one precise fragment and when they are relevant for the discussion.
Concerning the thermal pathway, it has been suggested that the internal energy of the analyte is correlated with the exothermicity of the proton exchange

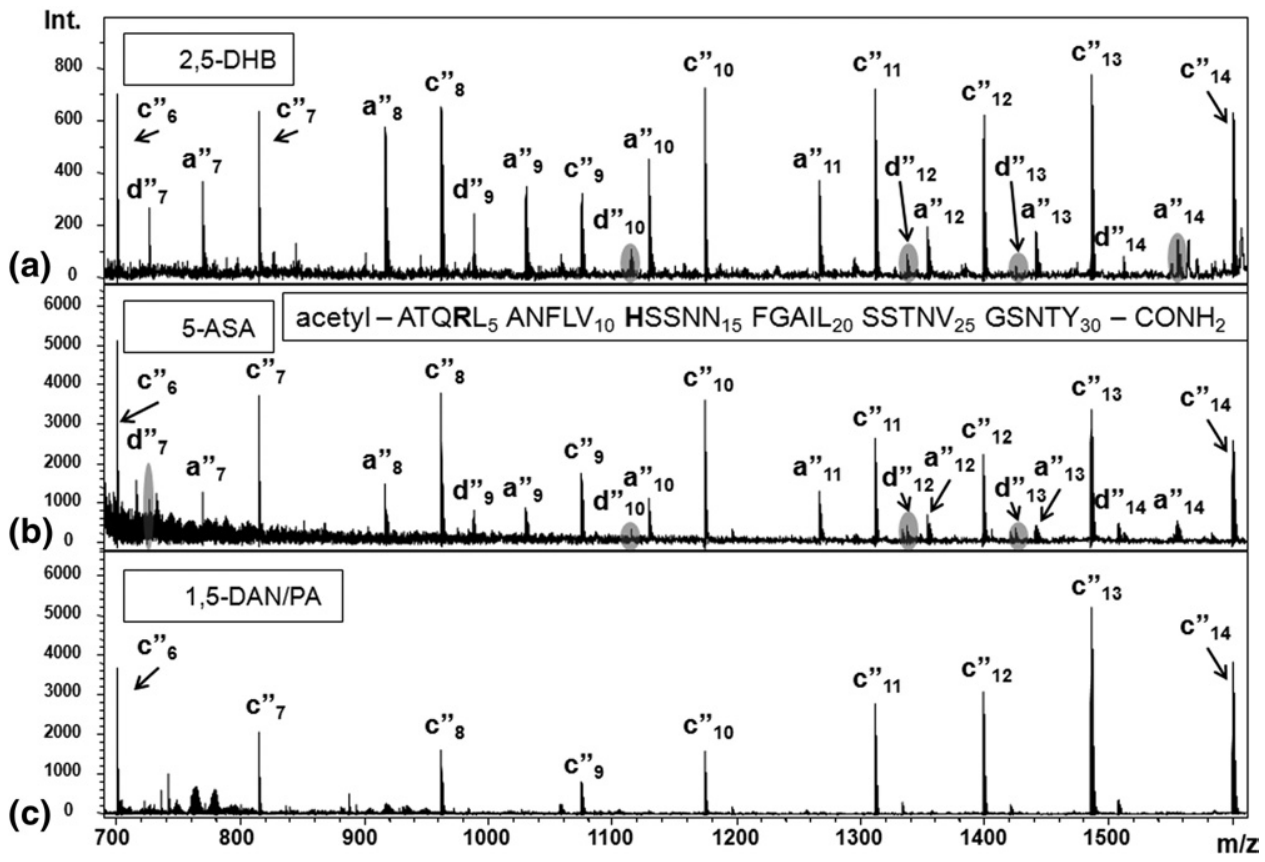

Figure 3. Zoom of the ISD spectra (in the positive ion mode) of the acetyl-Amylin (human) in the $690-1610 \mathrm{~m} / \mathrm{z}$ range in 2,5-DHB (a), in 5-ASA (b) and in 1,5-DAN/PA (c). The sequence of the peptide is indicated in the figure. 2, 5-DHB and 5-ASA produce more intense $a$ - and $d$-ions than 1,5-DAN/PA in which they are only poorly observed (non-annotated). 
from the matrix to the peptide evaluated with their respective gas-phase proton affinities (eq 3):

$$
\begin{gathered}
\mathrm{A}+[\mathrm{M}+\mathrm{H}]^{+} \rightarrow[\mathrm{A}+\mathrm{H}]^{+}+\mathrm{M} ; \\
\Delta \mathrm{H}^{0}=\mathrm{PA} \text { (matrix) - PA (analyte) }
\end{gathered}
$$

A matrix with a low proton affinity would give more internal energy to the analyte and thereby favor its fragmentation by the thermal pathway. It would therefore be qualified as a hot matrix. For classic matrices, the efficiencies in producing thermal fragments were compared with their respective proton affinities and the following correlation was observed [26]: CHCA (proton affinity $=812[26]-841[40] \mathrm{kJ} / \mathrm{mol})>2,5-\mathrm{DHB}(852$ [39] -856 [40] kJ/mol) $>$ SA (876 [40] -905 [26] $\mathrm{kJ} / \mathrm{mol}$ ). The proton affinities of 1,5-DAN and of 5-ASA were theoretically calculated (DFT) and their values show a correlation with their tendencies to produce thermal fragments: CHCA $(\mathrm{PA}=812$ [26] -841 [40] $\mathrm{kJ} / \mathrm{mol})>2,5-\mathrm{DHB}(852[39]-856[40] \mathrm{kJ} / \mathrm{mol}) \sim$ 5 -ASA $(877 \mathrm{~kJ} / \mathrm{mol})>\mathrm{SA}(876[40]-905$ [26] kJ/mol) $>$ 1,5 -DAN (942 kJ/mol). 5-ASA is as efficient as $2,5-\mathrm{DHB}$ whereas $1,5-\mathrm{DAN}$ is poorly efficient.

Here, the proton affinity ranking suffices to explain the efficiency of production of $a-, b-$, and $y$-ions, hence the difference in reactivity according to the thermal pathway. Note, however, that Sachon et al. [41] have recently shown with very labile peptides, that explaining the matrix influence on the in-source formation of $a-, b$ - and $y$-ions can in some instances require taking into account the matrix-dependent desorption dynamics (indicated by the initial axial velocity of the ions) mediating the low-energy collisions between the matrix and the analyte in the MALDI plume. It would therefore be interesting to measure the initial velocities (and temperatures) of matrix and analytes in 1,5-DAN and in 5-ASA.

\section{$d$-, w-Ions Formed from Consecutive Reaction Pathways}

As shown in Figures 2 and 3, a few $w$ - and $d$-type fragments are observed in the ISD spectra of peptides. $w$-Ions generated from some matrices can be very intense, as shown in Figure $4 \mathrm{~b}$, whereas $d$-ions are less often observed. $d$-Ions generated from 1,5-DAN are generally less intense than those generated from 2,5DHB (in Figure 3, d-ions generated from 1,5-DAN are very poorly observed and are not annotated). The matrix is therefore highly influent on the observation of these types of fragments.

The $w$ - and $d$-ions are very informative fragments involving a side-chain loss, the mass of which is specific to the amino acid $[42,43]$. These fragments can be very helpful to confirm an amino acid deduced from two successive $c$ - or $z$-ions, or for the distinction of the isobaric amino acids leucine and isoleucine. These types of fragments were previously reported in 193-nm laser photodissociation experiments on molecular ions produced by a classical MALDI source $\left(\mathrm{N}_{2}\right.$ laser) [44-47] but rarely reported in ISD-MALDI $[8,9]$. To determine the origin of $w$ - and $d$-ions, the ISD spectra of the different peptides used in 2,5-DHB and in 1,5-DAN were compared.

The fragment $w^{\prime \prime}{ }_{10}$ of the acetyl-Calpastatin (human) is not favored by the large increase of the thermal fragment $y^{\prime \prime}{ }_{10}$ observed in the 2,5-DHB matrix (Figure 2 ). Moreover the structure of $y^{\prime \prime}$-ions corresponds to the structure of a peptide and it is therefore very unlikely that these fragments further degrade to give $w$-ions. We propose that the $w$-ions come from the radical-induced pathway and are formed by the further degradation of the intermediate $z^{\bullet}$-ions involved in the radical-induced pathway (Scheme 1). w-Ions are, however, not always observed even if the corresponding $z$-ions are observed. According to the mechanism [42, 43] shown in Scheme $\mathbf{1}$, the radical fragment $z^{\bullet}$ gives the $w$-ion by the cleavage of the $C_{\beta}-C_{\gamma}$ bond of the residue of the amino acid followed by the loss of a radical part of the residue. Therefore, not all amino acid residues can lead to that fragmentation. When aromatic amino acids [histidine $(\mathrm{H})$, tyrosine $(\mathrm{Y})$, tryptophan $(\mathrm{W})$, phenylalanine $(\mathrm{F})]$ are involved, the $w$-ions are absent because the cleavage of the $\mathrm{C}_{\beta}-\mathrm{C}_{\gamma}$ bond corresponds to the difficult cleavage of a $\mathrm{CH}_{2}$-aryl bond. The $w$-ions are also absent with the amino acids glycine $(\mathrm{G})$, alanine $(\mathrm{A})$ because they do not possess a $C_{\beta}-C_{\gamma}$ bond. Although proline prevents the formation of $z$-ions, it can lead to the formation of $w$-ions by a rearrangement of the radical species [42]. Figure 2 illustrates the formation of $w$-ions from proline residues $\left(w^{\prime \prime}{ }_{8}\right.$ and $\left.w^{\prime \prime}{ }_{9}\right)$.

A $d$-ion is the $\mathrm{N}$-terminal equivalent to a $w$-ion. However, $d$-ions are less often observed (Figure 3 ). The fact that $d$-ions are favored in 2,5-DHB and 5-ASA, and not in 1,5-DAN, suggests that the formation of these fragments is linked to the thermal pathway, for example via degradation of $a_{n}$-ions into $d_{n}$-ions, as shown in Scheme 2. Nevertheless, this mechanism fails to explain the formation of all $d$-ions because only a few aminoacids possess a hydrogen in the $\delta$ position. The $d$-ions may therefore be formed by the radical-pathway as well. As shown in Scheme 1, the degradation of $c_{n}$-ions to $d_{n}$-ions involves the loss of an isocyanate function (OCNH). This mechanism of formation of $d$-ions therefore requires not only that the matrix efficiently produces radicals (to form the $\mathrm{c}^{\bullet}$-ion in the first place), but also that the matrix provides enough internal energy for the consecutive fragmentation to occur. This can explain the difference between 2,5-DHB and 1,5-DAN, and the lesser extent of these $d$-ions in 1,5-DAN that favors the radical pathway but has the highest proton affinity. Soltwisch et al. [48] recently studied the influence of the pressure on ISD in a MALDI source coupled to an orthogonal TOF mass spectrometer. They showed that contrarily to the radical-induced fragments, the thermal fragments are strongly influenced by the gas 

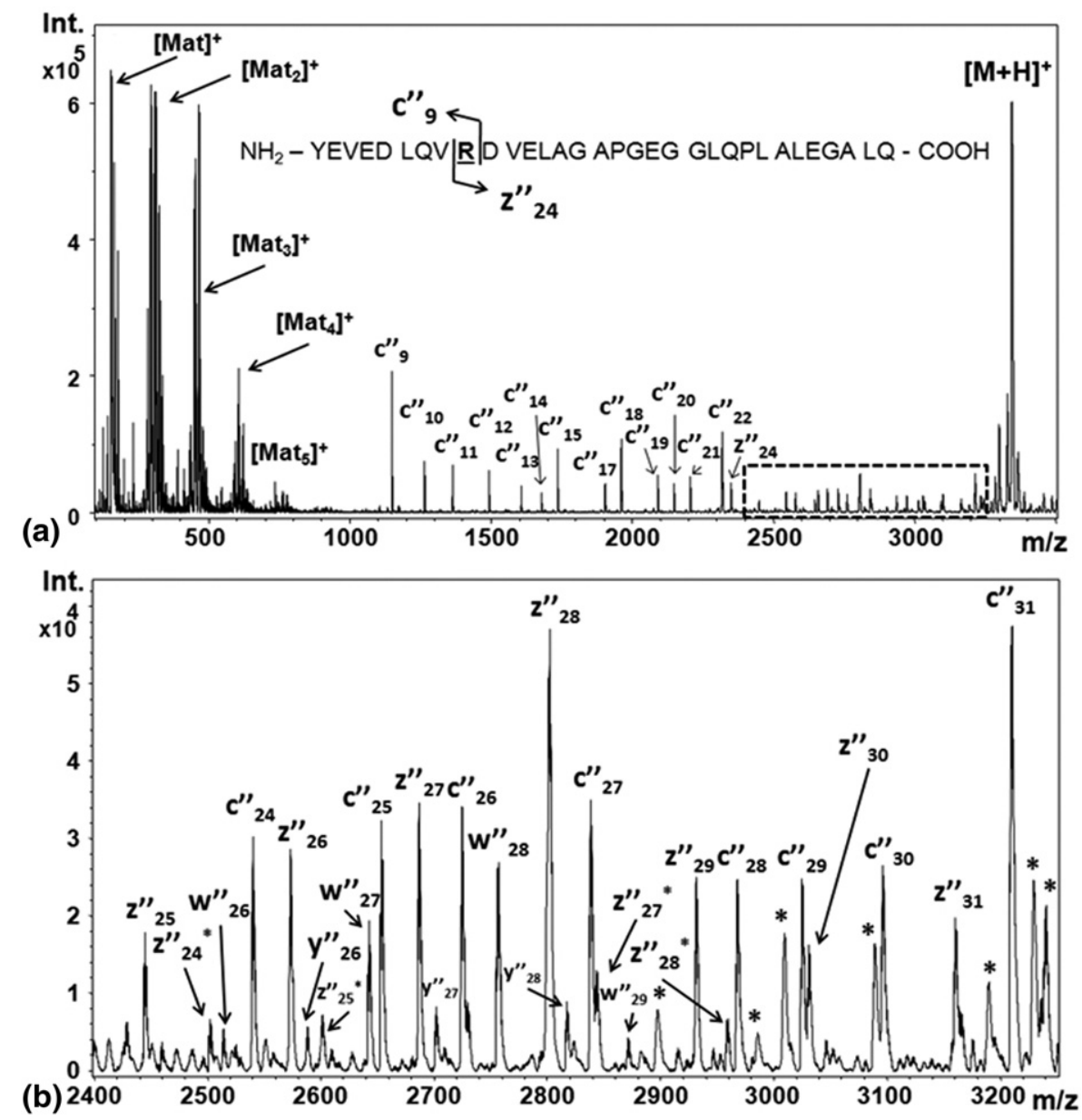

Figure 4. ISD spectrum of the $\left(\mathrm{Tyr}^{0}\right)$-C-peptide $(\mathrm{dog})$ in $1,5-\mathrm{DAN} / \mathrm{PA}$ in the positive ion mode. (a) Complete spectrum, (b) zoom in the box indicated in (a) $z^{\prime \prime *}$ corresponds to matrix adducts formed with the $z^{\prime}$ radical ions $\left(z^{\prime \prime}+156 \mathrm{Da}\right)$. [Mat $]_{\mathrm{x}}{ }^{+}$represents multimers of intact and fragmented matrix molecules. Their exact composition is difficult to determine due to the complex polymerization mechanism of 1,5-DAN [36].

pressure. However, they also showed that some ISD fragments issued from the radical-induced pathway can be influenced by the gas pressure similarly to the thermal fragments.

\section{Matrix Adducts on z-Ions}

In Figure $4 \mathrm{~b}$, the $z$-ions annotated with an asterisk $\left(z^{\prime \prime *}\right)$ correspond to $z$-ions plus $156 \mathrm{Da}$. These peaks correspond to $z^{\prime}$ radical ions that reacted with a radical of the 1,5-DAN matrix $[\mathrm{M}-\mathrm{H}]^{\bullet}$ leading to the stable matrix adduct species $z^{\prime}{ }_{x}+157$ that will be annotated $z^{\prime \prime}{ }_{x}+156$ to avoid any confusion about the $\mathrm{m} / \mathrm{z}$ ratios at which they are observed, as shown in Scheme 1. It must be noted that they are also observed in the negative ion mode $\left(z_{x}+156\right)$. Matrix adducts on $z$-ions were already reported by Kocher et al. [18] with the 2,5-DHB matrix, but were not reported yet with 1,5-DAN. The interesting aspect of these adducts is that they are observed for $z$-ions but not for $c$-ions. Therefore, the formation of these matrix adducts is linked to the structure (and reactivity) of $z$-ions and not to the sequence of the peptide. The fact that $z$-ions easily undergo a further degradation to $w$-ions or easily form adducts with the matrix explains why $z$-ions are often less intense than $c$-ions. Therefore, $c$-ions are generally easier to assign than $z$-ions in ISD spectra, as shown in Figure 4a. It is also noteworthy that as the intermediate $c^{\bullet}$ - and $z^{\bullet}$-ions (open-shell) are not observed in MALDI-MS, it is very likely that there are sufficient amounts of hydrogen radicals in the MALDI plume to form the corresponding closed-shell fragments (Scheme 1). Indeed, for the reduction of a disulfide bond, two hydrogen radicals are required because no partial reduction of the disulfide bond $(\ldots \mathrm{SH} \bullet \mathrm{S} \ldots$. .) is observed. Moreover, this reduction is achieved before the ion extraction is applied, as in the case of the formation of ISD fragments. As the radical-induced pathway is independent of the ionization process, all mechanisms presented in Scheme 1 can be transposed to the negative ion mode just by using deprotonated peptide species instead of the protonated species. 


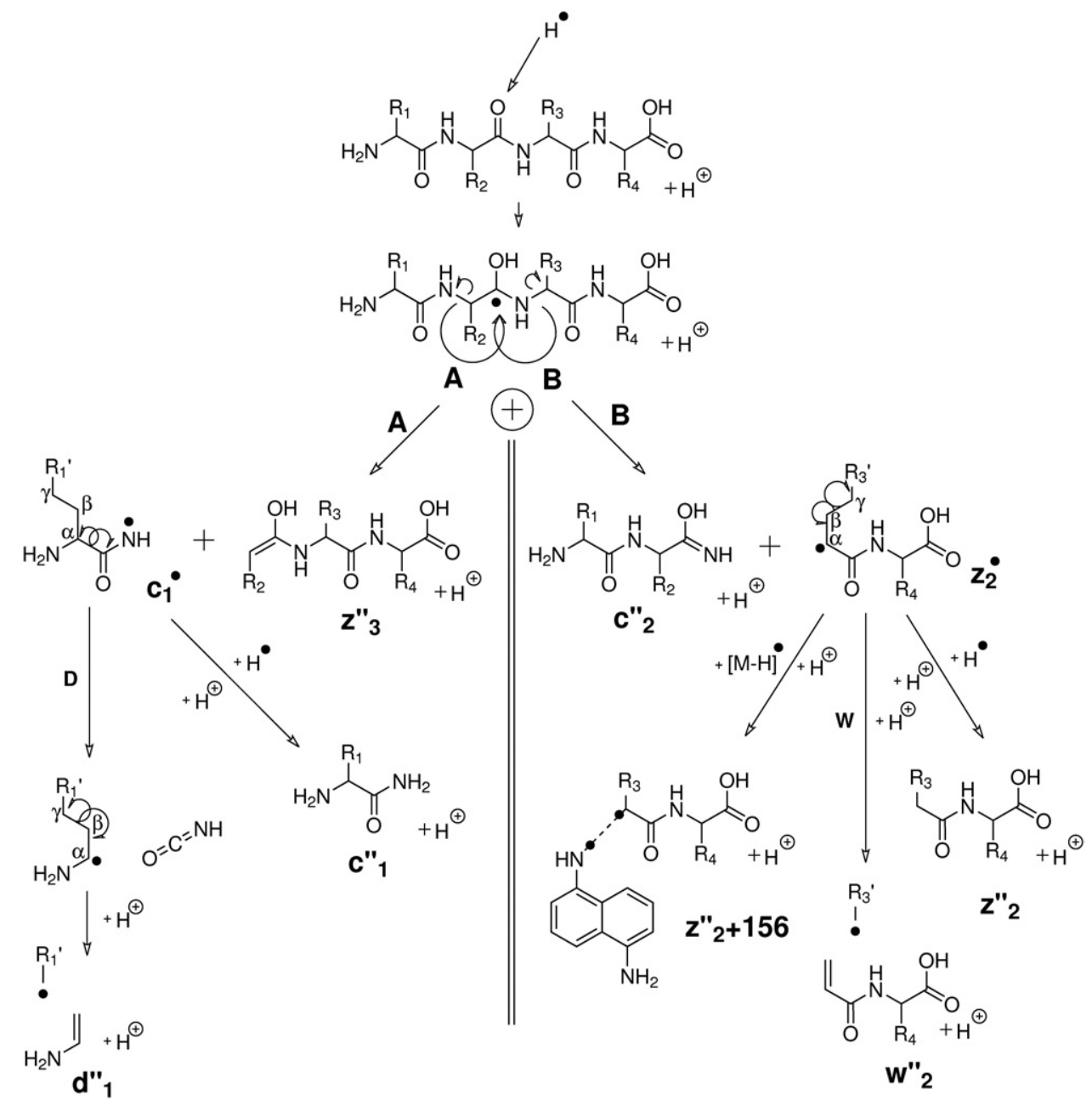

Scheme 1. The different mechanisms of fragmentation observed in the radical-induced pathway. After the hydrogen transfer onto the carbonyl, the peptide will cleave either at the $\mathrm{NH}-\mathrm{C}_{\alpha}$ bond on the $\mathrm{N}$-terminus side (A pathway) or at the $\mathrm{NH}-\mathrm{C}_{\alpha}$ bond on the $\mathrm{C}$-terminus side (B pathway). The $\mathrm{D}$ pathway represents the mechanism of formation of $d$-ions by the radical-induced pathway. The $\mathrm{W}$ pathway represents the mechanism of formation of $w$-ions. The formation of $d$-ions is favored in 2,5-DHB and 5-ASA because these matrices (low proton affinities) transfer more internal energy to the peptide, by proton exchange from the matrix to the peptide, facilitating the loss of the isocyanate moiety. As the radical-induced pathway is independent of the ionization process, all mechanisms presented in Scheme 1 can be transposed to the negative ion mode just by using deprotonated peptide species instead of the protonated species.

\section{Influence of the Peptide Sequence on the Relative Fragment Abundance-Positive ion Mode}

Even if ISD fragmentation can occur randomly on the peptide sequence (except in presence of a proline residue or a disulfide bond), the existence of a charged site on the ISD fragments is necessary for their observation. In positive ion mode, the presence of a basic amino acid residue [Arg (R), Lys (K), and His $(\mathrm{H})]$ in the peptide is necessary to observe its molecular ion and its ISD fragments. Figure 4 shows the spectrum of the peptide $\left(\mathrm{Tyr}^{0}\right)$-C-peptide (dog). The arginine (R) at position 9 is its only basic residue. Accordingly, the first fragments observed in the $c$ - and $z$-series are the fragments $c^{\prime \prime}{ }_{9}$ and $z^{\prime \prime}{ }_{24}$ because these fragments are the first in their respective series to contain the arginine residue.
For calcitonin I, the first $c$-ion observed is the fragment $c^{\prime \prime}{ }_{11}$, which is the first one to contain the lysine (K) residue at the position $11 . z^{\prime \prime}{ }_{9}$ is the first $z$-ion containing a basic amino acid residue, the arginine (R) at the position 24. The sequence of calcitonin (salmon I) is indicated in Figure 5. This peptide contains several basic amino acid residues and the most favored site of protonation (the most basic) is the arginine at position 24 . However, the fragment $c^{\prime \prime}{ }_{11}$ is observed despite the fact that it contains only a lysine at position 11 . Therefore all the basic amino acid residues can provide the positive charge when necessary. As the ions are mainly observed in the +1 charge state, when several sites of charge are available it is the most favored one that is charged. The $\mathrm{N}$-terminal $\mathrm{NH}_{2}$ function and the $\mathrm{C}$ - 


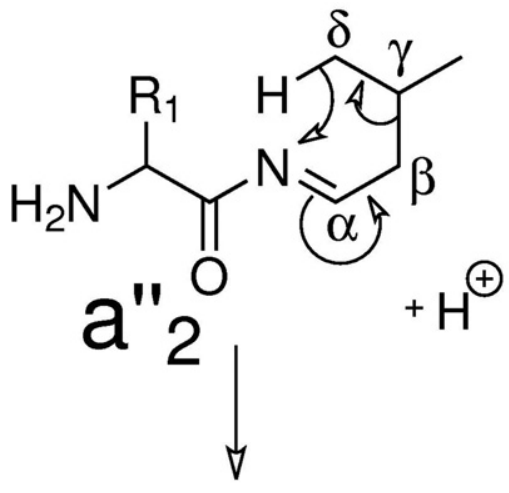<smiles>[R]C(N)C(=O)NC=C</smiles>

Scheme 2. Mechanism for the formation of $d$-ions from the thermal $a$-ions (case of the isoleucine amino acid residue). The formation of all $d$-ions cannot be explained by this mechanism as only few amino acids possess a hydrogen in the $\delta$ position.

terminal amidated carboxylic function $\left(\mathrm{CONH}_{2}\right)$ are not sufficient for the observation of the ISD fragments (e.g., fragments $c^{\prime \prime}{ }_{1}$ to $c^{\prime \prime}{ }_{8}$ are not observed for $\left(\mathrm{Tyr}^{0}\right)-\mathrm{C}-$ peptide $(\mathrm{dog}))$. The same behavior was observed with 2,5-DHB and 1,5-DAN for all peptides of Table 1.

The presence of an arginine residue (R) in an ISD fragment generally greatly increases its intensity. In Figure 5, the $c$-ions containing the arginine $\left(c^{\prime \prime}{ }_{24}\right.$ to $\left.c^{\prime \prime}{ }_{30}\right)$ are more intense on average than the ones that contain only histidine and/or lysine residues. Only one arginine residue is sufficient to obtain an ISD spectrum of a peptide in the positive ion mode even if the peptide contains acidic amino acid residues as shown for the $\left(\mathrm{Tyr}^{0}\right)$-C-peptide (dog) (Figure 4). Amongst the arginine containing fragments (i.e., $z_{9}^{\prime \prime}$ to $z^{\prime \prime}{ }_{31}$ and $c^{\prime \prime}{ }_{24}$ to $c^{\prime \prime}{ }_{30}$ ), large variations of the intensities are nevertheless observed.

\section{Influence of the Peptide Sequence on the Relative Fragment Abundance-Negative Ion Mode}

1,5-DAN is a far better matrix than 2,5-DHB for the acquisition of ISD spectra in the negative ion mode [27]. The higher gas-phase proton affinities of 1,5-DAN $(942$ $\mathrm{kJ} / \mathrm{mol}$ ) compared with those of 2,5-DHB (852-856 $\mathrm{kJ} / \mathrm{mol})$ and of 5 -ASA $(877 \mathrm{~kJ} / \mathrm{mol})$ could explain why this matrix is more efficient to produce deprotonated analyte species. However, the proton affinities are calculated for the electronic ground state. The ionization process in MALDI and the explanation of the influence of the matrix on the extent of negatively and positively

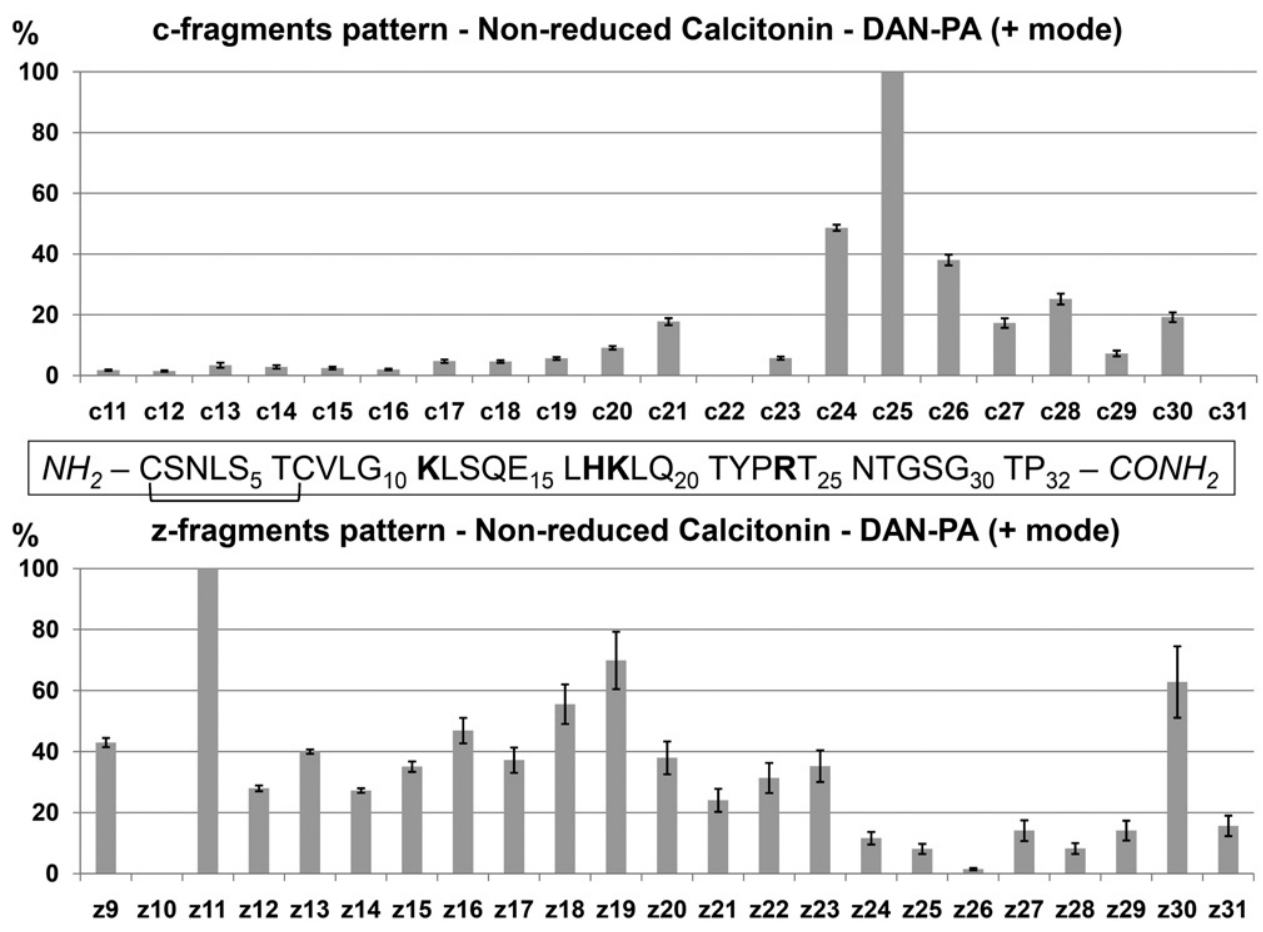

Figure 5. Patterns of the radical-induced ISD $c$ - and $z$-ions for the calcitonin (salmon I) in the positive ion mode. $c^{\prime \prime}{ }_{22}, c^{\prime \prime}{ }_{31}$ and $z^{\prime \prime}{ }_{10}$ are not observed because of the presence of proline residues at positions 23 and 32. The relative abundances of the fragments (in percent) were calculated by the ratio of their areas to the area of the most intense fragment normalized to $100 \%$. The error bars represent the standard deviations calculated from 15 measurements (5 ISD spectra on three different MALDI spots). 
Table 1. Sequences of the different peptides used to determine the influence of the peptide sequence as well as the mechanisms of formation of the various fragment types observed in ISD

\begin{tabular}{|c|c|c|c|}
\hline Peptide & & Sequence $^{a}$ & \\
\hline Calcitonin (salmon I) (3431.9 Da) & $\mathrm{NH}_{2}-$ & $\begin{array}{l}\text { CSNLS }_{5} \text { TCVLG }_{10} \text { KLSQE }_{15} \text { LHKLO }_{20} \\
\text { TYPRT }_{25} \text { NTGSG }_{30} \text { TP }_{32}\end{array}$ & $-\mathrm{CONH}_{2}$ \\
\hline Oxidized insulin $\beta$ chain (bovin) (3493.6 Da) & $\mathrm{NH}_{2}-$ & 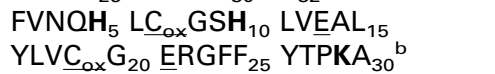 & $-\mathrm{COOH}$ \\
\hline АCTH (7-38) (human) (3659.2 Da) & $\mathrm{NH}_{2}-$ & $\begin{array}{l}\text { FRWGK }_{5} \text { PVGKK }_{10} \text { RRPVK }_{15} \\
\text { VYPNG }_{20} \text { AEDES }_{25} \text { AEAFP }_{30} \text { LE }_{32}\end{array}$ & $-\mathrm{COOH}$ \\
\hline (Glu $)$-Fibrinopeptide B (1570.6 Da) & $\mathrm{NH}_{2}-$ & EGVND $_{5}$ NEEGF $_{10}$ FSAR $_{14}$ & $-\mathrm{COOH}$ \\
\hline$\left(T_{y r}{ }^{0}\right)-C$-peptide $(\mathrm{dog})(3337.7 \mathrm{Da})$ & $\mathrm{NH}_{2}-$ & $\begin{array}{l}\text { YEVED } \\
\text { APGEG }_{20} \text { LLVRD }_{10} \text { VELLAG }_{25} \text { ALEGA }_{30} \text { LO }_{32}\end{array}$ & $-\mathrm{COOH}$ \\
\hline Acetyl-calpastatin (184-210) (human) (3177.7 Da) & Acetyl - & $\begin{array}{l}\underline{D P M S S}_{5} \mathrm{TYIEE}_{10} \mathrm{LGKR}_{15} \mathrm{VTIPP}_{20} \\
\text { KYREL }{ }_{25} \mathrm{LA}_{27}\end{array}$ & $-\mathrm{CONH}_{2}$ \\
\hline$\beta$-Endorphin (rat) (3466.1 Da) & $\mathrm{NH}_{2}-$ & $\begin{array}{l}\text { YGGFM }_{5} \text { TSEKS }_{10} \text { OTPLV }_{15} \\
\text { TLFKN }_{20} \text { AIIKN }_{25} \text { VHKKG }_{30} \mathrm{Q}_{31}\end{array}$ & $-\mathrm{COOH}$ \\
\hline Acetyl-amylin (human) (8-37) (3225.5 Da) & Acetyl - & $\begin{array}{l}\text { ATORL }_{5} \text { ANFLV }_{10} \text { HSSNN }_{15} \text { FGAIL }_{20} \\
\text { SSTNV }_{25} \text { GSNTY }_{30}\end{array}$ & $-\mathrm{CONH}_{2}$ \\
\hline Neuropeptide W30 (rat) (3559.2 Da) & $\mathrm{NH}_{2}-$ & $\begin{array}{l}\text { WYKHV }_{5} \text { ASPRY }_{10} \text { HTVGR }_{15} \\
\text { ASGLL }_{20} \text { MGLRR }_{25} \text { SPYLW }_{30}\end{array}$ & $-\mathrm{COOH}$ \\
\hline GLP-2 (rat) (3796.2 Da) & $\mathrm{NH}_{2}-$ & $\begin{array}{l}\text { HADGS }_{5} \text { FSDEM }_{10} \text { NTILD }_{15} \\
\text { NLATR }_{20} \underline{\text { DFINW }}_{25} \text { LIOTK }_{30} \text { ITD }_{33}\end{array}$ & $-\mathrm{COOH}$ \\
\hline Amyloid $\beta$-protein (1-28) (3262.5 Da) & $\mathrm{NH}_{2}-$ & 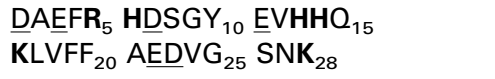 & $-\mathrm{COOH}$ \\
\hline
\end{tabular}

a Basic amino acids [arginine (R), histidine $(\mathrm{H})$, and lysine $(\mathrm{K})$ ] are given in bold print; Acidic amino acids [aspartic acid (D) and glutamic acid (E)] are underlined.

${ }^{b} \mathrm{C}_{\mathrm{ox}}$ corresponds to oxidized cysteines; i.e., to cysteic acid $\left(-\mathrm{SO}_{3} \mathrm{H}\right)$.

charged species is still widely discussed as recently pointed out and revisited by Hillenkamp et al. [49].

In the negative ion mode, the influence of the basicity/acidity of amino acids is less straightforward than in the positive ion mode. The presence of an acidic amino acid is not necessary for the observation of ISD fragments. For example, for oxidized insulin $\beta$-chain, $c$-ions are observed starting at the sixth residue, even though $c_{6}\left(\mathrm{NH}_{2}-\mathrm{FVNQHL}\right)$ does not contain any acidic amino acid. $z$-Ions start from the position 22 , and the fragment $z_{9}$ contains only the carboxylic acid function of the C-terminal part of the peptide (RGFFYTPKA$\mathrm{COOH})$. These results suggest that contrarily to the positive ion mode, the acidic terminal functions can provide the negative charge. The $\mathrm{C}$-terminal carboxylic acid function and the $\mathrm{COH}-\mathrm{NH}$ and $\mathrm{CO}-\mathrm{NH}_{2}$ (represented in Scheme 1) functions seem therefore sufficient to observe $c$ - and $z$-ions, respectively, in the negative ion mode. Nevertheless, the fragments containing acidic amino acids are generally more intense, particularly those containing a cysteic acid (oxidized cysteine) that largely increase the negative ion signals [27].

\section{Combined Influences of the Peptide and of the Matrix on the ISD Fragments Patterns}

The matrices do not only influence the extent of both fragmentation pathways. Their impact on the relative intensities of the different ISD fragments is actually broader. Indeed, the ISD spectra of a same peptide in the various matrices are quite different. For example, Figure 6 shows the relative intensities of the $c$-ions observed for the ACTH [7-38] (human) in 2,5-DHB and in 1,5-DAN. This contrasts with the absence of matrix effects on the fragmentation patterns in PSD. PSD spectra of the $\left(\mathrm{Glu}^{1}\right)$-Fibrinopeptide $\mathrm{B}$ in different matrices were acquired and these spectra are very similar whatever the matrix is used and are shown in Supplementary material Figure S-3.

The differences observed for the radical-induced ISD fragments patterns according to the matrix can therefore not only be explained by the primary structure of the peptide. A matrix-dependent structural effect related to the interactions between the matrix and the amino acid residues in the matrix crystals can therefore be invoked. Indeed, PSD fragmentation is mainly activated by collisions with neutrals during the ion extraction. The strong matrix effect indicates that radicalinduced ISD fragmentation occurs much earlier in the desorption/ionization process, when the plume is much denser and where peptide matrix noncovalent interactions are still numerous. The effect of peptidematrix interactions and the effect of peptide secondary structure on the ISD patterns clearly warrant further investigations.

\section{Conclusion}

The comparison between several efficient ISD matrices led to new insights in the ISD fragmentation processes. The present paper shows that:

(a) It is possible to selectively favor the fragmentation pathways: (1) matrices with high hydrogen donor 


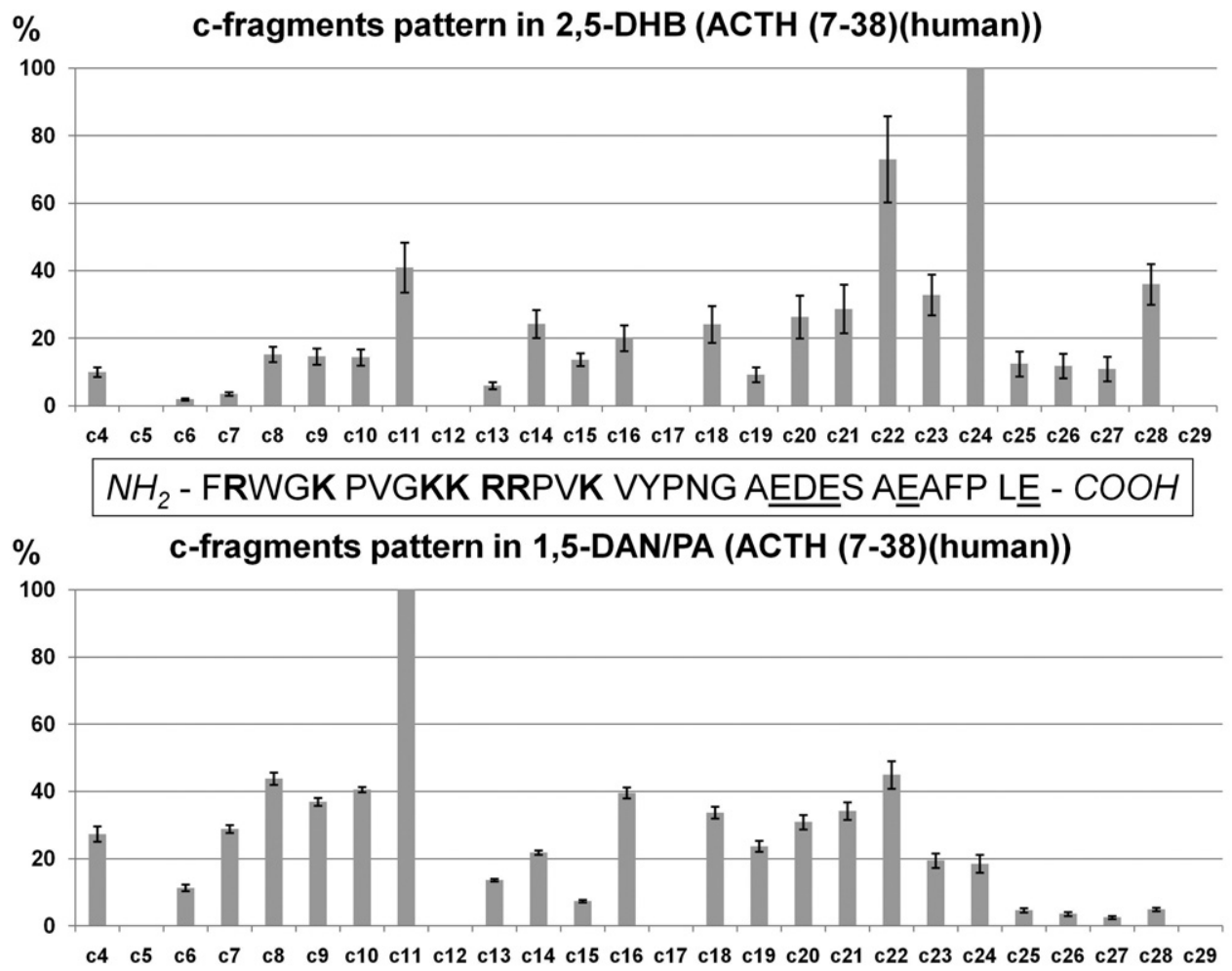

Figure 6. Patterns of the $c$-ions of the ACTH (7-38) (human) in 2,5-DHB and in 1,5-DAN/PA in the positive ion mode. $c^{\prime \prime}{ }_{5}, c^{\prime \prime}{ }_{12}, c^{\prime \prime}{ }_{17}$, and $c^{\prime \prime}{ }_{29}$ are not observed because of the presence of proline residues at positions $6,13,18$, and 30 , respectively. The relative abundances of the fragments (in percent) were calculated by the ratio of their areas to the area of the most intense fragment normalized to $100 \%$. The error bars represent the standard deviations calculated from 15 measurements (5 ISD spectra on three different MALDI spots).

abilities, such as 1,5-DAN and 5-ASA, favor the radical-induced pathway $(c-, z$ - and $w$-type fragments) and (2) matrices with low proton affinities, as 2,5-DHB and 5-ASA matrices, favor the thermal pathway (a-, $b-$, and $y$-type fragments) and the formation of the $d$-type fragments from $c$-ions.

(b) It is possible to determine, for a given peptide, which fragments will be observed or not. The location of the acidic and/or basic amino acids in the peptide sequence determines which ISD fragments can be positively or negatively charged and therefore observed in the positive or negative ion mode, respectively. The amino acids that could undergo a side-chain loss to give $w$-ions can also be determined. As $d$-ions are less often observed, it remains difficult to predict their observation.

(c) For an unknown peptide, the complementary use of matrices favoring one and/or the other pathway can facilitate the interpretation of complex ISD spectra. As discussed in point a, the use of 1,5-DAN will give mainly radical-induced ISD fragments $(c-$ and $z$-ions) of the peptide and 2,5-DHB or 5-ASA will produce more intense thermal fragments $(a-$, $b$-, and $y$-ions). A differential analysis of ISD spectra of a peptide in both matrix types (e.g., in 1,5-DAN and in 2,5-DHB) can help to distinguish the differ- ent fragment types and to assign consecutive fragments of the same type.

(d) The extra $d$ - and $w$-ions, more easily observed in efficient ISD matrices (1,5-DAN for the $w$-ions and 2,5-DHB and 5-ASA for the $d$-ions), can help (1) to confirm some amino acid residues of a determined sequence and/or (2) to distinguish isoleucine (I) from leucine (L).

\section{Acknowledgments}

K.D. acknowledges the FRIA (Fonds de la Recherche dans l'Industrie et l'Agriculture, Belgium) for a Ph.D. fellowship. V.G. is a Research Associate of the FNRS (Fonds National de la Recherche Scientifique, Belgium). The FNRS and Walloon Region contributed the mass spectrometry facility funding. The authors thank Frédéric Rosu for assistance with the theoretical calculations.

\section{Appendix A Supplementary Material}

Supplementary material associated with this article may be found in the online version at doi:10.1016/j. jasms.2010.07.009. 


\section{References}

1. Karas, M.; Hillenkamp, F. Laser Desorption Ionization of Proteins with Molecular Masses Exceeding 10,000 Daltons. Anal. Chem. 1988, 60(20), 2299-2301.

2. Karas, M.; Bachmann, D.; Bahr, U.; Hillenkamp, F. Matrix-Assisted Ultraviolet-Laser Desorption of Nonvolatile Compounds. Int. J. Mass Spectrom. Ion Processes 1987, 78, 53-68.

3. Zenobi, R.; Knochenmuss, R. Ion Formation in MALDI Mass Spectrometry. Mass Spectrom. Rev. 1998, 17(5), 337-366.

4. Lennon, J. J.; Walsh, K. A. Direct Sequence Analysis of Proteins by In-Source Fragmentation During Delayed Ion Extraction. Protein Sci. 1997, 6(11), 2446-2453.

5. Reiber, D. C.; Grover, T. A.; Brown, R. S. Identifying Proteins Using Matrix-Assisted Laser Desorption/Ionization In-Source Fragmentation Data Combined with Database Searching. Anal. Chem. 1998, 70(4), 673-683.

6. Reiber, D. C.; Brown, R. S.; Weinberger, S.; Kenny, J.; Bailey, J. Unknown Peptide Sequencing Using Matrix-Assisted Laser Desorption/Ionization and In-Source Decay. Anal. Chem. 1998, 70(6), 1214-1222.

7. Gross, J.; Strupat, K. Matrix-Assisted Laser Desorption/Ionization Mass Spectrometry Applied to Biological Macromolecules. Trac-Trend Anal. Chem. 1998, 17(8/9), 470-484.

8. Takayama, M.: Tsugita, A. Sequence Information of Peptides and Proteins with In-Source Decay in Matrix Assisted Laser Desorption/ Ionization Time of Flight-Mass Spectrometry. Electrophoresis 2000, 21(9), 1670-1677.

9. Hardouin, J. Protein Sequence Information by Matrix-Assisted Laser Desorption/Ionization In-Source Decay Mass Spectrometry. Mass Spectrom. Rev. 2007, 26(5), 672-682.

10. Brown, R. S.; Lennon, J. J. Sequence-Specific Fragmentation of MatrixAssisted Laser-Desorbed Protein Peptide Ions. Anal. Chem. 1995, 67(21), 3990-3999.

11. Brown, R. S.; Feng, J. H.; Reiber, D. C. Further Studies of In-Source Fragmentation of Peptides in Matrix-Assisted Laser Desorption-Ionization. Int. J. Mass Spectrom. Ion Processes 1997, 169, 1-18.

12. Suckau, D.; Resemann, A.; Schuerenberg, M.; Hufnagel, P.; Franzen, J.; Holle, A. A novel MALDI LIFT-TOF/TOF Mass Spectrometer for Proteomics. Anal. Bioanal. Chem. 2003, 376(7), 952-965.

13. Rouse, J. C.; Yu, W.; Martin, S. A. A Comparison of the Peptide Fragmentation Obtained from a Reflector Matrix-Assisted Laser Desorption-Ionization Time-of-Flight and a Tandem 4-Sector Mass Spectrometer. J. Am. Soc. Mass Spectrom. 1995, 6(9), 822-835.

14. Franzen, J.; Frey, R.; Holle, A.; Krauter, K. O. Recent Progress in Matrix-Assisted Laser Desorption Ionization Postsource Decay. Int. I. Mass Spectrom. 2001, 206(3), 275-286.

15. Roepstorff, P.; Fohlman, J. Proposal for a Common Nomenclature for Sequence Ions in Mass-Spectra of Peptides: Biomedical Mass Spectrometry. J. Biomed. Mass Spectrom. 1984, 11, 601-601.

16. Biemann, K. Contributions of Mass-Spectrometry to Peptide and Protein Structure. Biomed. Environ. Mass Spectrom. 1988, 16(1/12), 99-111.

17. Takayama, M. N-C $(\alpha)$ Bond Cleavage of the Peptide Backbone Via Hydrogen Abstraction. J. Am. Soc. Mass Spectrom. 2001, 12(9), 10441049.

18. Kocher, T.; Engstrom, A.; Zubarev, R. A. Fragmentation of Peptides in MALDI In-Source Decay Mediated by Hydrogen Radicals. Anal. Chem. 2005, 77(1), 172-177

19. Takayama, M.; Tsugita, A. Does In-Source Decay Occur Independent of the Ionization Process in Matrix-Assisted Laser Desorption? Int. J. Mass Spectrom. 1998, 181, L1-L6.

20. Takayama, M. In-Source Decay Characteristics of Peptides in MatrixAssisted Laser Desorption/Ionization Time-of-Flight Mass Spectrometry. J. Am. Soc. Mass Spectrom. 2001, 12(4), 420-427.

21. Spengler, B.; Kirsch, D.; Kaufmann, R. Metastable Decay of Peptides and Proteins in Matrix-Assisted Laser-Desorption Mass-Spectrometry. Rapid Commun. Mass Spectrom. 1991, 5(4), 198-202.

22. Paizs, B.; Suhai, S. Fragmentation Pathways of Protonated Peptides. Mass Spectrom. Rev. 2005, 24(4), 508-548.

23. Kruger, N. A.; Zubarev, R. A.; Horn, D. M.; McLafferty, F. W. Electron Capture Dissociation of Multiply Charged Peptide Cations. Int. J. Mass Spectrom. 1999, 187, 787-793.

24. Syrstad, E. A.; Turecek, F. Toward a General Mechanism of Electron Capture Dissociation. J. Am. Soc. Mass Spectrom. 2005, 16(2), 208-224.

25. Gabelica, V.; Schulz, E.; Karas, M. Internal Energy Build-Up in MatrixAssisted Laser Desorption/Ionization. J. Mass Spectrom. 2004, 39(6), $579-593$.

26. Schulz, E.; Karas, M.; Rosu, F.; Gabelica, V. Influence of the Matrix on Analyte Fragmentation in Atmospheric Pressure MALDI. J. Am. Soc. Mass Spectrom. 2006, 17(7), 1005-1013.

27. Demeure, K.; Quinton, L.; Gabelica, V.; De Pauw, E. Rational Selection of the Optimum MALDI Matrix for Top-Down Proteomics by In-Source Decay. Anal. Chem. 2007, 79(22), 8678-8685

28. Quinton, L.; Demeure, K.; Dobson, R.; Gilles, N.; Gabelica, V.; De Pauw, E. New Method for Characterizing Highly Disulfide-Bridged Peptides in Complex Mixtures: Application to Toxin Identification from Crude Venoms. J. Proteome Res. 2007, 6(8), 3216-3223.
29. Sakakura, M.; Takayama, M. In-Source Decay and Fragmentation Characteristics of Peptides Using 5-Aminosalicylic Acid as a Matrix in Matrix-Assisted Laser Desorption/Ionization Mass Spectrometry. J. Am. Soc. Mass Spectrom. 2010, 21(6), 979-988.

30. Calba, P. J.; Muller, J. F.; Hachimi, A.; Lareginie, P.; Guglielmetti, R. Spirooxazines as a Molecular Probe for the Study of Matrix-Assisted Laser Desorption/Ionization Processes. 1. Study of the Interaction Effect Between the Molecular Probe and the Matrix. Rapid Commun. Mass Spectrom. 1997, 11(14), 1602-1611.

31. Calba, P. J.; Muller, J. F.; Inouye, M. H-Atom Transfer Following Analyte Photoionization in Matrix-Assisted Laser Desorption/Ionization Processes. Rapid Commun. Mass Spectrom. 1998, 12(22), 1727-1731.

32. Fukuyama, Y.; Iwamoto, S.; Tanaka, K. Rapid Sequencing and Disulfide Mapping of Peptides Containing Disulfide Bonds by using 1,5Diaminonaphthalene as a Reductive Matrix. J. Mass Spectrom. 2006, 41(2), 191-201.

33. Knochenmuss, R.; Zenobi, R. MALDI Ionization: The Role of In-Plume Processes. Chem. Rev. 2003, 103(2), 441-452.

34. Stevenson, E.; Breuker, K.; Zenobi, R. Internal Energies of Analyte Ions Generated from Different Matrix-Assisted Laser Desorption/Ionization Matrices. J. Mass Spectrom. 2000, 35(8), 1035-1041.

35. Laskin, J.; Yang, Z. B.; Lam, C.; Chu, I. K. Charge-Remote Fragmentation of Odd-Electron Peptide Ions. Anal. Chem. 2007, 79(17), 6607-6614.

36. Azzem, M. A.; Yousef, U. S.; Limosin, D.; Pierre, G. Electro-Oxidative Oligomerization of 1,5-Diaminonaphthalene in Acetonitrile Medium. J. Electroanal. Chem. 1996, 417(1/2), 163-173.

37. See the pollution information site, http://www.scorecard.org/chemicalprofiles/(CAS number of 1,5-DAN: 2243-62-1)

38. Frisch, M. J. T.; G. W.; Schlegel, H. B.; Scuseria, G. E.; Robb, M. A Cheeseman, J. R.; Montgomery, J. A. Jr.; Vreven, T.; Kudin, K. N.; Burant, J. C.; Millam, J. M.; Iyengar, S. S.; Tomasi, J.; Barone, V.; Mennucci, B.; Cossi, M.; Scalmani, G.; Rega, N.; Petersson, G. A.; Nakatsuji, H.; Hada, M.; Ehara, M.; Toyota, K.; Fukuda, R.; Hasegawa, J.; Ishida, M.; Nakajima, T.; Honda, Y.; Kitao, O.; Nakai, H.; Klene, M. Li, X.; Knox, J. E.; Hratchian, H. P.; Cross, J. B.; Bakken, V.; Adamo, C.; Jaramillo, J.; Gomperts, R.; Stratmann, R. E.; Yazyev, O.; Austin, A. J.; Cammi, R.; Pomelli, C.; Ochterski, J. W.; Ayala, P. Y.; Morokuma, K.; Voth, G. A.; Salvador, P.; Dannenberg, J. J.; Zakrzewski, V. G.; Dapprich, S.; Daniels, A. D.; Strain, M. C.; Farkas, O.; Malick, D. K.; Rabuck, A. D.; Raghavachari, K.; Foresman, J. B.; Ortiz, J. V.; Cui, Q.; Baboul, A. G.; Clifford, S.; Cioslowski, J.; Stefanov, B. B.; Liu, G.; Liashenko, A. Piskorz, P.; Komaromi, I.; Martin, R. L.; Fox, D. J.; Keith, T.; Al-Laham, M. A.; Peng, C. Y.; Nanayakkara, A.; Challacombe, M.; Gill, P. M. W.; Johnson, B.; Chen, W.; Wong, M. W.; Gonzalez, C.; Pople, J. A.; Gaussian 03, Revision D. 02; Gaussian, Inc.: Wallingford CT, 2004.

39. Bourcier, S.; Hoppilliard, Y. B3LYP DFT Molecular Orbital Approach, an Efficient Method to Evaluate the Thermochemical Properties of MALDI Matrices. Int. J. Mass Spectrom. 2002, 217(1/3), 231-244.

40. Mirza, S. P.; Raju, N. P.; Vairamani, M. Estimation of the Proton Affinity Values of 15 Matrix-Assisted Laser Desorption/Ionization Matrices Under Electrospray Ionization Conditions Using the Kinetic Method. J. Am. Soc. Mass Spectrom. 2004, 15(3), 431-435.

41. Sachon, E.; Clodic, G.; Blasco, T.; Jacquot, T.; Bolbach, G. In-Source Fragmentation of Very Labile Peptides in Matrix-Assisted Laser Desorption/Ionization Time-of-Flight Mass spectrometry. Anal. Chem. 2009, 81(21), 8986-8992.

42. Johnson, R. S.; Martin, S. A.; Biemann, K.; Stults, J. T.; Watson, J. T. Novel Fragmentation Process of Peptides by Collision-Induced Decomposition in a Tandem Mass-Spectrometer-Differentiation of Leucine and Isoleucine. Anal. Chem. 1987, 59(21), 2621-2625.

43. Johnson, R. S.; Martin, S. A.; Biemann, K. Collision-Induced Fragmentation of $(\mathrm{M}+\mathrm{H})^{+}$Ions of Peptides-Side-Chain Specific Sequence Ions. Int. J. Mass Spectrom. Ion Processes 1988, 86, 137-154.

44. Cui, W. D.; Thompson, M. S.; Reilly, J. P. Pathways of Peptide Ion Fragmentation Induced by Vacuum Ultraviolet Light. J. Am. Soc. Mass Spectrom. 2005, 16(8), 1384-1398.

45. Moon, J. H.; Yoon, S. H.; Kim, M. S. Photodissociation of Singly Protonated Peptides at $193 \mathrm{~nm}$ Investigated with Tandem Time-ofFlight Mass Spectrometry. Rapid Commun. Mass Spectrom. 2005, 19(22), 3248-3252.

46. Choi, K. M.; Yoon, S. H.; Sun, M. L.; Oh, J. Y.; Moon, J. H.; Kim, M. S. Characteristics of Photodissociation at $193 \mathrm{~nm}$ of Singly Protonated Peptides Generated by Matrix-Assisted Laser Desorption Ionization (MALDI). J. Am. Soc. Mass Spectrom. 2006, 17(12), 1643-1653.

47. Thompson, M. S.; Cui, W. D.; Reilly, J. P. Factors that Impact the Vacuum Ultraviolet Photofragmentation of Peptide Ions. J. Am. Soc. Mass Spectrom. 2007, 18(8), 1439-1452.

48. Soltwisch, J.; Souady, J.; Berkenkamp, S.; Dreisewerd, K. Effect of Gas Pressure and Gas Type on the Fragmentation of Peptide and Oligosaccharide Ions Generated in an Elevated Pressure UV/IR-MALDI Ion Source Coupled to an Orthogonal Time-of-Flight Mass Spectrometer. Anal. Chem. 2009, 81(8), 2921-2934.

49. Hillenkamp, F.; Wafler, E.; Jecklin, M. C.; Zenobi, R. Positive and Negative Analyte Ion Yield in Matrix-Assisted Laser Desorption/ Ionization Revisited. Int. J. Mass Spectrom. 2009, 285(3), 114-119. 